\title{
Laser application in high temperature materials
}

\author{
Roland W. Ohse \\ Commission of the European Communities \\ Joint Research Centre, Karlsruhe Establishment \\ European Institute for Transuranium Elements \\ Postfach 2340, D-7500 Karlsruhe, Federal Republic of Germany
}

\begin{abstract}
The scope and priorities of laser application in materials science and technology are attracting widespread interest. After a brief discussion of the unique capabilities of laser application in the various fields of materials science, main emphasis is given on the three areas of materials processing, surface modification and alloying, and property measurements at high temperatures.
\end{abstract}

In materials processing the operational regimes for surface hardening, drilling, welding and laser glazing are discussed.

Surface modifications by laser melting, quenching and surface alloying, the
formation of solid solutions, metastable phases and amorphous solids on the basis
of rapid solidification, ion implantation and ion beam mixing are considered. The
influence of solidificaton rates and interface velocities on the surface properties
are given.

The extension of property measurements up to and beyond the melting point of refractory materials into their critical region by a transient-type dynamic laser pulse heating technique is given for the three examples of vapour pressure measurement, density and heat capacity determination in the solid and liquid phases. A new approach, the laser autoclave technique, applying laser heating and $x$-ray shadow technique under autoclave conditions to acoustically levitated spheres will be presented.

\section{INTRODUCTION}

Since the development of the laser in the 1960's a rapid expansion of research interests and applications in science and technology took place. The diversified development of gas, liquid and solid state lasers (ref.1), operating over a large wavelength range from the infrared to the ultraviolet spectral region with peak powers up to terawatt $(1012 \mathrm{~W})$ focussed to $1017 \mathrm{~W} \mathrm{~cm} \mathrm{-2} \mathrm{at} \mathrm{ultra-short} \mathrm{pulse}$ generation (ref.2), led to an extremely wide range of applications in physics, material science, spectroscopy, chemical technology, biochemistry and molecular biology.

Due to its high intensity, monochromaticity, and tunability the laser has become one of the most powerful tools in physics and chemistry. The difference in the absorption spectra of atoms and molecules, permitting their selective excitation, forms the basis for selective detection, selective chemical reaction, and selective separation by selective laser photophysics and photochemistry (refs.3-5).

Tunable coherent radiation for ultra-high resolution spectroscopy (refs.6,7) is available from the UV to the IR spectrum using semiconductor diode laser, spin-flip laser based on stimulated Raman scattering, high pressure gas laser, three and four-wave frequency mixing, solid state colour centres, excimer and dye laser as the most widely used tunable sources (refs.8,9).

Because of their unique capabilities tunable lasers are gaining widespread acceptance to air pollution surveillance both in remote sensing and in situ monitoring (ref.10). Laser monitoring of pollutants in the troposphere and stratosphere will become increasingly important (ref.9). The detection, quantification and destruction of supertoxic chemicals by photolysis are of utmost importance and worldwide interest.

Previously unresolved ultra-fast photophysical and photochemical reactions can be studied by subpicosecond $(10-12 \mathrm{sec})$ laser spectroscopy such as vibrational dynamics of molecules and lattices, photobiological mechanisms and picosecond electronic processes in semiconductors.

Private address: Weinbergstrasse 4, D-7770 Überlingen/Bodensee, Federal Republic of Germany 
Multiphoton laser-induced chemistry has found widespread application in laser-induced chemical reactions and isotopic separation.

In laser chemistry energy can be delivered directly into the reaction pathway coupled at the precise frequency to the reacting atoms or molecules thus achieving excellent efficiency in the laser stimulated chemical reaction and therefore high yields of the desired product.

The multiphoton laser isotope separation as a selective multistep photoionization process involves the selective isotope excitation of the atomic or molecular vapour beam, and the ionization of the excited isotope. The separation, extraction and collection of the ions on the ion extractor collector plate is accomplished by an electromagnetic field. The tunable laser frequencies are generated in a dye laser system which in turn is driven by a pump laser system (ref.11).

Properties under high pressure such as the equation of state, new structures and chemical reactions can be studied by laser-driven shockwave loading (adiabatic compression) for shock pressures up to terapascal ( $1 \mathrm{TPa}=107$ bar) previously obtainable only by nuclear explosions (refs.12-15).

For controlled thermonuclear fusion reactions high-intensity $(10 \mathrm{~kJ}, 100 \mathrm{ps}) \mathrm{Nd}$ : glass laser of $100 \mathrm{~mm}$ diameter disk modules of 100 TW are under construction for laser compression of deuterium-tritium pellets to pressures of 1012 bar and temperatures of $108 \mathrm{~K}$. X-ray laser-irradiated target experiments on vapour deposited Se with a nominal pulse length of $450 \mathrm{ps}$ and incident intensity of $5.1013 \mathrm{~W} / \mathrm{cm}^{2}$ exhibited substantial amplifications at 206,3 and $209,6 \AA$ (refs. 15,16).

This conference is concerned with high temperature and energy-related materials. Every aspect of energy production, its extraction, processing, refining and conversion depends on materials performance matched to the needs of the process. The standard of living in our society depends on the efficient consumption of energy. The necessity for efficient energy utilization leads to large-scale conversion of energy resources and increase in operating temperatures. This can only be achieved by improved designs and better materials, i.e. progress and innovations in materials science. Main emphasis is given on the three areas of laser material processing, described in section 2 , laser surface modification and alloying, given in section 3 , and property measurements at high temperatures treated in section 4 .

Laser material processing (refs.17,18) is finding an increasingly wide field of application in surface hardening, drilling, cutting, micromachining and welding. The objective of drilling, cutting and micro-machining is to remove material by evaporation. Power densities of $106 \mathrm{~W} \mathrm{~cm}^{-2}$ at low order transverse mode are required to allow precise machining. Laser welding ranges from pulsed welding of small electronic components at high repetition and production rates to continuous multikilowatt $\mathrm{cw} \mathrm{CO}_{2}$ laser deep-penetration welding.

Metastable structure synthesis by rapid quenching (ref.19), condensation (vapour, sputter, electrochemical) and irradiation (particle bombardment, ion implantation, ion beam mixing) has opened the most promising and exciting era yet encountered in physical metallurgy. Rapid quenching provides the means for tailoring properties, previously unobtainable, to meet specific material requirements. Here containerless laser processing with high quenching speeds drastically widens the area of application. The improvement of surface sensitive properties such as mechanical properties as microhardness, wear resistance, corrosion protection or optical properties can be achieved by laser surface alloying processing at high quenching rates and resolidification interface velocities. Laser processing allows the production of surface layers with a wide range of structures and compositions on a variety of substances of radically different nature than by methods using conventional metallurgy. In addition it allows surface equivalents of established bulk alloys and, therefore, a conservation of strategic and nobel metals. With high cooling rates amorphous metals and alloys and other nonequilibrium materials can be synthesized from melts. Containerless processing avoids surface catalysed crystallisation in the preparation of amorphous materials from liquids. The materials concerned are advanced materials such as intermetallic compounds, borids, carbides, nitrides, silicides, oxides and unique ceramics, glasses, metals, alloys, electronic and optical materials. Diverse commercial opportunities result from the unprecedented purity and uniformity of new chemical compositions and physical states of matter that can thus be achieved.

Future progress in high temperature technologies depends largely on the materials performance and on the availability of reliable thermophysical, thermochemical and thermodynamic high temperature data (ref.20). This is of extreme importance at very high temperatures where data can differ dramatically from predictions based on extrapolations of low temperature data. At temperatures beyond the melting point of refractory materials property measurements lead to a number of severe additional constraints imposing short heating times by transient-type dynamic pulse heating techniques (refs.21,22). For this transient-type heat generation to very high temperatures pulsed laser irradiations proved to be well suited. The well defined temporal and spatial power density distribution of a laser, operating in its ground mode (Gaussian profile), is excellently suited for property measurements at high temperatures. The extension of property measurements up to $5000 \mathrm{~K}$ will be demonstrated for vapour pressure measurements using laser pulse heating, multi-wavelength pyrometry, mass spectrometry, Langmuir probe and high tension diode studies under vacuum (refs.23,24), and density and heat capacity (ref.25) determinations by multibeam laser pulse heating, $\mathrm{x}$-ray shadow technique, and six-wavelength pyrometry under high pressure autoclave conditions to containerless acoustically levitated spheres (ref.26). 


\section{LASER MATERIAL PROCESSING}

The unique advantage of laser material processing such as localized heat zone and the ability to weld dissimilar materials and geometries has led to a comprehensive worldwide research and industrial application (refs.17,18,27,28). The main areas are laser drilling, cutting, micromachinig, and laser welding given in section 2 , and laser surface modifications, treated in section 3 , such as laser annealing, laser hardening, laser surface melting (laser glazing), and laser surface alloying. A classification of laser processing is given in Table 1 . The basic lasers for material processing are summarized in Table 2 .

Table 1: Classification of Laser Processing

\section{Sub-Melting}

Surface hardening

Surface annealing

\section{Melting}

Coating, cladding

Surface alloying

Welding

Soldering

\section{Vaporization}

Drilling
Scribing
Micromachining
Cutting
Marking (Engraving)
Shock hardening

Table 2: Laser for Material Processing

\begin{tabular}{|c|c|c|c|c|}
\hline \multicolumn{2}{|c|}{$\begin{array}{l}\text { Type of laser } \\
\text { operational } \\
\text { mode }\end{array}$} & \multirow{2}{*}{$\begin{array}{c}\begin{array}{c}\text { Wavelength } \\
\mu \mathrm{m}\end{array} \\
10.6 \\
10.6\end{array}$} & \multirow{2}{*}{$\begin{array}{c}\begin{array}{c}\text { Pulse } \\
\text { duration(s) }\end{array} \\
10 \cdot 6\end{array}$} & \multirow{2}{*}{$\begin{array}{c}\begin{array}{c}\text { Power (W) } \\
\text { pulse energy (J) } \\
\text { (upper limit) }\end{array} \\
20 \mathrm{~kW} \\
400 \mathrm{~J}\end{array}$} \\
\hline $\begin{array}{l}\mathrm{CO}_{2} \\
\mathrm{CO}_{2} \text { (TEA) }\end{array}$ & $\begin{array}{l}\mathrm{cw} \\
\mathrm{p}\end{array}$ & & & \\
\hline Nd: YAG & $\begin{array}{l}\mathrm{cw} \\
\mathrm{p} \\
\mathrm{Q} \\
\mathrm{p} \\
\mathrm{Q}\end{array}$ & $\begin{array}{l}1.06 \\
1.06 \\
1.06 \\
1.06 \\
1.06\end{array}$ & $\begin{array}{l}- \\
10^{-3} \\
10^{-8} \\
10^{-3} \\
10^{-8}\end{array}$ & $\begin{array}{rl}1 & \mathrm{~kW} \\
100 & \mathrm{~J} \\
1 & \mathrm{~J} \\
300 & \mathrm{~J} \\
50 & \mathrm{~J}\end{array}$ \\
\hline Ruby & $\begin{array}{l}\mathrm{p} \\
\mathrm{Q}\end{array}$ & $\begin{array}{l}0.6943 \\
0.6943\end{array}$ & $\begin{array}{l}10^{-4} \\
10^{-8}\end{array}$ & $\begin{array}{r}120 \mathrm{~J} \\
15 \mathrm{~J}\end{array}$ \\
\hline Argon Ion & $\mathrm{cw}$ & $\begin{array}{l}0.488 \\
0.5145\end{array}$ & - & $15 \mathrm{~W}$ \\
\hline $\begin{array}{c}\text { Excimer } \\
\mathrm{XeCl} \\
\mathrm{KrF} \\
\mathrm{ArF}\end{array}$ & $\begin{array}{l}Q \\
Q \\
Q\end{array}$ & $\begin{array}{l}0.308 \\
0.248 \\
0.193\end{array}$ & $\begin{array}{l}10^{-9} \\
10^{-9} \\
10^{-9}\end{array}$ & $\begin{array}{ll}1 & J \\
1 & J \\
1 & J\end{array}$ \\
\hline
\end{tabular}

\subsection{Basic aspects}

For process optimization, to fully exploit the economic potential of laser material processing, the areas of laser beam characteristics, material properties, and gas jet assistance need careful investigation.

The main laser processing parameter are wavelength, mode configuration, power density, focal spot diameter (ref.29), pulse duration, divergence and polarisation (ref.30).

For material processing the wavelength plays a significant role in determining the suitability of a laser for a particular application. Since the reflectance of most metals (Fig.1) increases with wavelength more power will be required from a laser with longer wavelength (ref.30).

The transverse mode configuration determines the spatial power density distribution across the beam (ref.30). A low order transverse mode is necessary to guarantee precise cutting. Optimum machining efficiency can be obtained by a Gaussian beam intensity profile of a laser operating in the single transversal TEM $_{00}$ mode. The power density across the focal spot diameter, defined as $1 / \mathrm{e}^{2}$ of the peak height, and the pulse duration depend on the particular material processing application.

For drilling as a material removal process, high power density and a short pulse duration are required to vaporize the material and to limit the heat affected zone. In contrast welding requires the material to be melted but not vaporized. This is best accomplished at lower intensity with relatively long pulse durations to guarantee sufficient heat transfer for melting. In gas-jet laser cutting with continuous high power $\mathrm{cw} \mathrm{CO}_{2}$ laser of $100 \mathrm{~W}$ to $10 \mathrm{~kW}$ material is removed through either the melting, vaporization or sublimation process at temperatures ranging from the melting to the boiling point. The operational regimes for material processing are summarized in Fig.2.

The main material properties are absorption of laser light, thermal conductivity and diffusivity, melting and boiling temperature, vapour pressure, heat of transition (fusion and vaporization), and chemical properties, especially if active gases such as oxygen are involved for gas-jet assisted laser cutting (ref.30). The absorption of the laser beam depends on wavelength, temperature, power density, angle of incident, and plane of polarization (ref.31). At room temperature and small power density the absorption of a $\mathrm{CO}_{2}$ laser beam normal to the surface lies for most metals below $20 \%$. It strongly depends on surface roughness and impurities. At the boiling point the absorption strongly increases. At power densities of $108 \mathrm{~W} / \mathrm{cm}^{2}$ the absorption is close to 1 and almost independent of the metal. This is explained by the formation of a thin absorbing plasma layer (ref.32). 


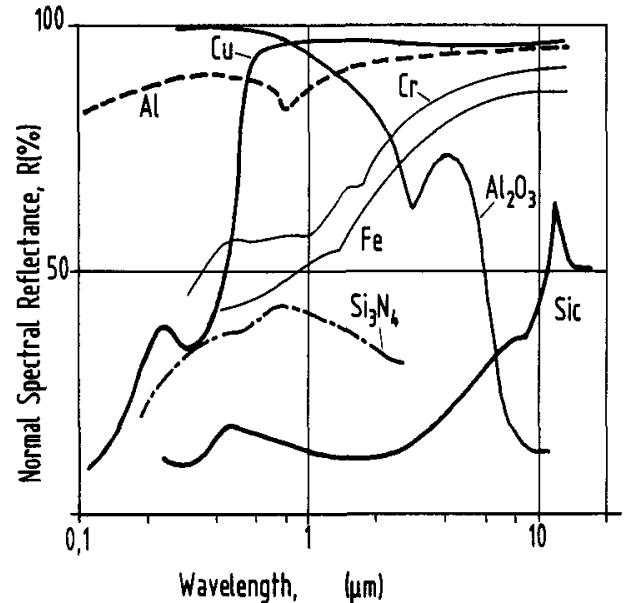

Fig.1: Normal spectral Reflectance as a Function of Wavelength (refs.28,30)

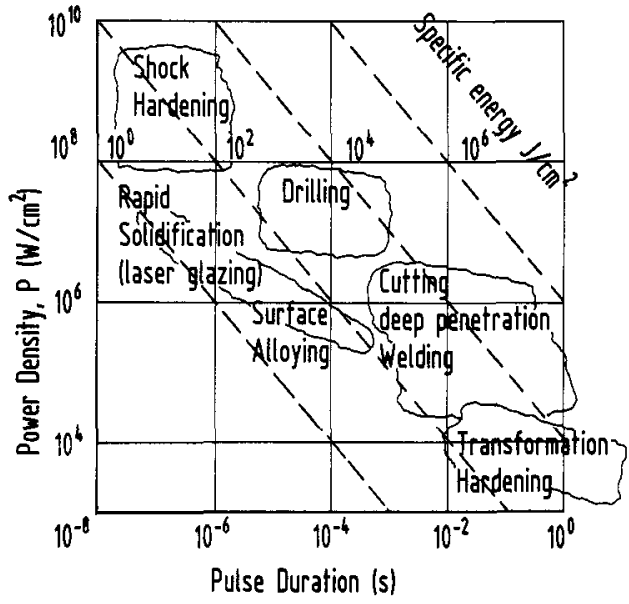

Fig.2: Operational Regimes in Laser Material Processing (refs. $30,34,48,51$ )

\subsection{Laser drilling}

In one of the first industrial applications flash pumped Nd:YAG laser were used in watch industry to drill ruby stones in the pulsed mode of operation achieving hole diameter of about $30 \mu \mathrm{m}(\mathrm{ref} .33)$. Since then laser drilling with hole diameters ranging from 0.01 to $1.0 \mathrm{~mm}$ has become a major tool for processing high temperature resistant materials, superalloys, tungsten, molybdenum, steel, ceramic materials such as silicium nitride, high-temperature fired alumina, etc. (ref.34).

Laser drilling is performed in the pulsed mode of operation using mainly solid state Nd:glass, the high repetition rate $\mathrm{Nd}: Y A G$ and $\mathrm{CO}_{2}$ gas laser. Pulse lengths are of the order of $100 \mu \mathrm{s}$ to $1 \mathrm{~ms}$, and in the Q-switched mode 5 to $250 \mathrm{~ns}$. The extremely high power densities of Nd:YAG laser are able to melt and vaporize practically all materials even at high reflectance. The pulsed mode of operation confines the heat to the hole region and avoids absorption of laser light in the plume of vaporized material which puts an upper limit to material removal in a single pulse with increasing power. A schematic display of the gas-jet and vacuum assisted laser drilling is given in Fig. 3 . The mechanisms proposed for material removal range from shockwave propagation, liquid ejection to explosive removal with subsurface temperatures exceeding the surface temperature leading to subsurface vaporization of localized areas.

High precision drilling has been achieved using repetitive laser pulses at lower power levels and low order transverse mode. Additional improvements in industrial processing are expected from robotic manipulation coupled with glas fiber system for beam conduction.

\subsection{Laser cutting and micromachining}

In the majority of industrial applications of laser cutting (refs.30,35) a gas stream, concentric with the focussed laser beam, is used to purge the melted, evaporated or sublimated material from the laser cut as shown in Fig.4 (ref.36). This gas-jet assisted laser cutting process can either be performed by an inert gas jet or by a reactive gas jet. The inert gas-jet assisted laser cutting process is used to avoid burning damage of flammable materials. The reactive gas-jet assisted laser cutting process takes advantage of the energy supplied by the exothermic chemical reaction of the gas jet with the material being removed (e.g. $\mathrm{Ti}+\mathrm{O}_{2} \rightarrow \mathrm{TiO}_{2}, 2 \mathrm{Fe}+\mathrm{O}_{2} \rightarrow 2 \mathrm{FeO}$ ). Cutting of stainless steel is performed with a high pressure oxygen stream coaxial with the focussed laser beam at pressures of 2 to 5 bar (ref.37). The main processing parameter apart from material and thickness are position of the focal spot relative to the laser cut, power density, cutting rate, and gas jet pressure.

High power $\mathrm{cw} \mathrm{CO} 2$ laser of 100 to $500 \mathrm{~W}$, in a few applications up to $10 \mathrm{~kW}$, permit cutting rates of several meter per minute for material thickness up to $10 \mathrm{~mm}$. Excellent results were obtained in lowcarbon steel, zircaloy, titanium, tungsten, molybdenum and ceramic materials such as $\mathrm{Si}_{3} \mathrm{~N}_{4}, \mathrm{Al}_{2} \mathrm{O}_{3}$. Computer aided design and manufacturing (CAD/CAM) of arbitrarily complex objects with laserbased diagnostics and processing techniques such as laser cutting are applied to produce physical models of biomedical objects (ref.38).

The generation of intricate, highy complex patterns in thin-film and semiconductor circuit processing by micromachinig has been demonstrated and successfully applied in semiconductor industry. Laser are beginning to move into the area of high-precision dimensional analysis of circuit features and interferometric alignment of masks by the use of linewidths below $1 \mu \mathrm{m}$ for $4 \mathrm{Mbit}$ chip development. Nd:YAG based processing systems aimed at high-density memory repair of applications specific ICs. Laser scribing presents a well established technique to shape especially brittle materials, and separate individual components of discrete electronic devices fabricated on a single wafer or substrate. 


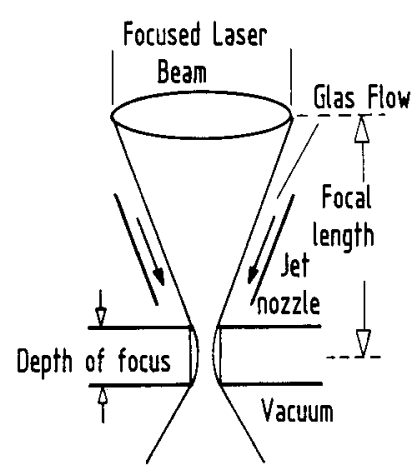

Fig.3: Air-jet and vacuum assisted laser drilling (refs.28,34)

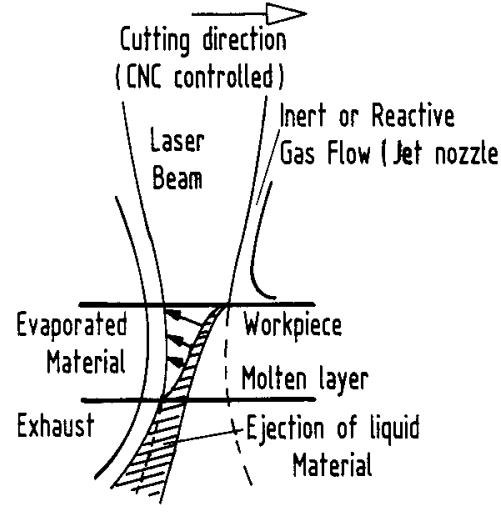

Fig.4: Gas-jeł assisted laser cutting (refs.35,36)

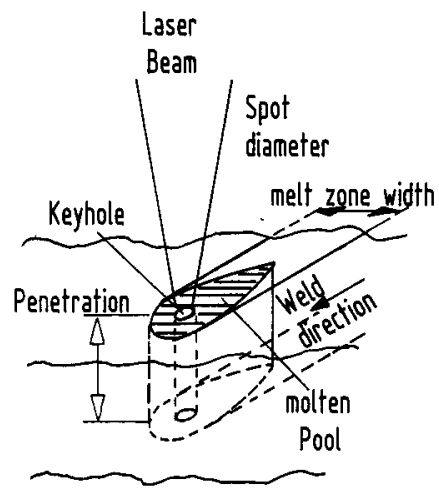

Fig.5: Deep penetration laser welding (refs.46,47)

The main goals are improved device yield, automated part identification and accelerated chip development by laser repair and laser-based diagnostics. Excimer (ArF $193 \mathrm{~nm}$ ), diode-pumped Nd:YAG $(1.06 \mu \mathrm{m})$ and argon-ion laser $(488,514.5 \mathrm{~nm})$ are promising candidates for high performance processing techniques in the semiconductor industry (Table 2).

\subsection{Laser welding}

The application of laser welding (ref.39) ranges from the micro-scale spot welding of small components and integrated circuits at high production rates and thin film technology to an upper limit of large-scale deep-penetration welding given by fusion depth and required weld penetration (ref.40). Multikilowatt laser welding is undergoing an intense development (refs.41,42). A special application of multikilowatt $\mathrm{CO}_{2}$ laser cutting for nuclear fuel disassembly includes remote alignment with teleoperated servomanipulators under hot-cell conditions (ref.43). The rapid progress of production applications in the automobile and electric industry is now expanding into the steel making industry (ref.44). Laser welding offers a high speed, low distortion technique suitable for automation, which cannot be satisfied by conventional welding techniques such as TIG, flash-butt, plasma arc etc. (ref.45).

Laser welding is accomplished by a "keyhole" mechanism in which the beam penetrates completely through the workpiece (Fig.5). As the workpiece moves relative to the beam the molten metal at the impingement area, supported by the vapour pressure and surface tension, flows behind the keyhole where it rapidly solidifies forming the weld bead. The plasma above the keyhole is suppressed by a jet of inert gas (ref.46). For most metals a power density of $106 \mathrm{~W} / \mathrm{cm}^{2}$ is required to produce the keyhole (ref.40).

The weld characteristics are bead profile, depth of penetration, weld width, integrity and microstructure, depending on power density, mode structure, focused spot size, weld speed, and plasma control by the gas jet. The parametric data are optimized on behalf of the weld bead profiles for narrow uniform full-penetration weldments with highest depth to width ratio at minimum heat input. The narrow fusion zone in relation to weld depth considerably reduces material distortion compared to arc welding techniques. Undesirably coarse grain structures are avoided both by rapid self-cooling and the grain refinement through the reversible allotropic transformation observed for iron and most steels during heating and cooling.

High power continuous wave $\mathrm{CO}_{2}$ laser, in multi-mode or single mode with power levels ranging up to $20 \mathrm{~kW}$ are used with either a robotic beam delivery system passing the focussed beam over the stationary workpiece or CNC controlled xyz table moving the workpiece under the stationary beam. Single-pass weld penetration to $2.5 \mathrm{~cm}$ and thin material welding speeds to $15 \mathrm{~m} / \mathrm{min}$ were demonstrated (ref.47).

\section{SURFACE MODIFICATION}

In surface engineering the tribological behaviour of surfaces, covering the fields of friction, wear resistance, fatique and lubrication, i.e. their near-surface mechanical behaviour as well as the corrosive, catalytic and optical behaviour, are of technical, economic and scientific interest (ref.48).

For the modification of these surface properties innovations based on laser and ion beam techniques (ref.49), aside classical techniques such as thin coatings and thermochemical diffusion treatment are 
attracting wide spread interest for future commercial utilization. Laser surface hardening by rapid quenching, laser surface alloying (ref.50) in conjunction with ion implantation and rapid solidification, as methods for metastable structure synthesis, provide the means for tailoring properties, previously unobtainable, to meet specific material requirements.

\subsection{Laser surface hardening and annealing}

The most important application of laser heat treatment below the melting point of the workpiece are laser surface hardening and laser annealing (refs.51,52). In case of cast iron and steel the surface layer is heated to above its austenite transformation temperature, still below the solidus temperature, and is then allowed to cool rapidly to form the very hard martensite phase (ref.53). The penetration depth of this solid state transformation hardening depends on the temperature profile during laser heating, starting at the temperature at which austenitization beginns to fully hardened material at the temperature of complete austenitization. In contrast to laser cutting where a low order mode, ideally a Gaussian power profile is required to achieve precise cutting, in laser hardening a uniform irradiation of rectangular spot dimension, using cylindrical lenses, is necessary to obtain constant thickness of the hardened layer across the entire width of the band.

The major advantage of laser hardening is selective hardening even of complex geometries by controlled heat input and irradiation at minimal mechanical deformation (ref.30). The same applies to laser annealing (ref.54) where selective heating permits recrystallisation of amorphous layers, damage removal of restricted regions, or redistribution of dopants in ion-implanted (ref.55) semiconductors.

\subsection{Laser surface alloying}

Laser surface alloying (LSA) is an exciting new process where the surfaces of relatively inexpensive substrates are modified by adding small amounts of alloying elements to a pool of molten metal produced by local melting. The high power density of a focussed laser beam is used to melt a thin overcoat and portion of the underlying substrate to the required depth to mix and alloy the constituents in the coating and substrate to a surface alloy of the desired composition and thickness. Surface alloys are typically 50 to several hundred micrometers in depth. The thermophysical properties of importance for LSA (refs.50,56,57) are thermal diffusivity, melting point, vapour pressure and normal spectral reflectance.

Quench rates, depending on the layer thickness of 104 to $1011 \mathrm{~K} / \mathrm{s}$ with resolidification velocities of up to $20 \mathrm{~m} / \mathrm{s}$ (refs.50,56-58) can be achieved by laser pulses of nano to microsecond pulse duration. Quench rates as high as 1013 to $1014 \mathrm{~K} / \mathrm{s}$ were reported on rapid solidification laser processing when the molten overlays are formed in situ on metal surfaces by short high energy laser pulses in the nano to picosecond range (ref.59). The high cooling rates by rapid self-quenching and resolidification offer the possibility of generating a wide variety of chemical and microstructural states including extended solid solutions, metastable crystalline phases, and amorphous metals (metallic glasses) (ref. 60). Rapid self-quenching by short laser pulses of the Q-switched (ns) and mode-locked (ps) laser (ref.56) led to sufficiently high cooling rates and interface velocities to suppress both epitaxial regrowth and crystallite nucleation from the melt during the resolidification process to form metallic glasses. Lin, Spaepen and Turnbull (refs.61-64) used the ps output of a mode-locked Nd:YAG laser to produce amorphous thin-film multilayers in the $\mathrm{Ni}-\mathrm{Nb}$, Mo-Ni, Mo-Co and $\mathrm{Nb}$-Co binary systems with a composition range larger than that produced by conventional splat-cooling techniques (refs.51,56,65,66).

Coatings have been accomplished by various techniques (ref.67) such as addition of alloying material, condensation and irradiation. A controlled addition of pre-alloyed material can be achieved by predeposition prior to laser melting or by a continuous codeposition of material by particle or wire injection to the melt zone at the time of laser treatment (Fig.6) (refs. 50,56,57,68).

Condensation techniques include vapour, electrochemical and sputter deposition. Among the principle irradiation methods of structure synthesis are structural damage by irradiation, ion implantation and ion beam mixing techniques.

The structural and compositional changes in the near-surface region can be induced by direct highdose $\left(\sim 1017\right.$ ions $\left./ \mathrm{cm}^{2}\right)$ ion implantation, the use of ion beams to intermix a deposited thin film on the substrate and by simultaneous deposition of material and ion bombardment. Higher concentrations can be obtained by the second method of depositing a thin film on the substrate and then mixing the film and substrate by ion implantation to enhance adhesion at the interface (ref.69).

Ion implantation doping of semiconductors ( $\mathrm{Si}, \mathrm{Ge}, \mathrm{III}-\mathrm{V}$ compounds) in the electronic industry (ref.56) is by far the most important application. Fatique-lifetime improvements of steel and carbide tools by high-dose nitrogen-ion implantation is of direct commercial and economic interest (ref.70). Chromium ion implantation has shown to reduce pitting corrosion of steels in marine environment (ref.71). Ion implantation of non-toxic biocompatible substances to prostheses is of interest in the medical field (ref.72). 
a)

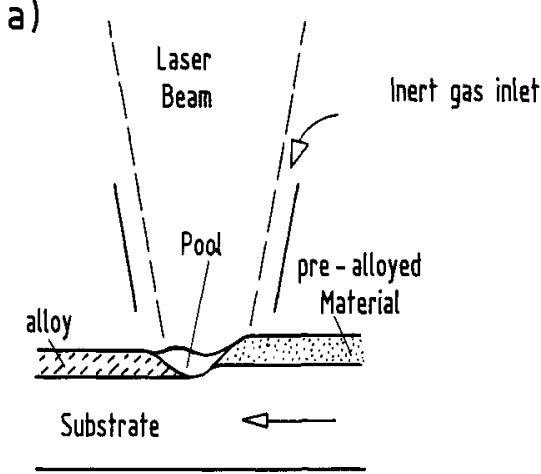

Fig.6: Laser surface alloying and cladding by

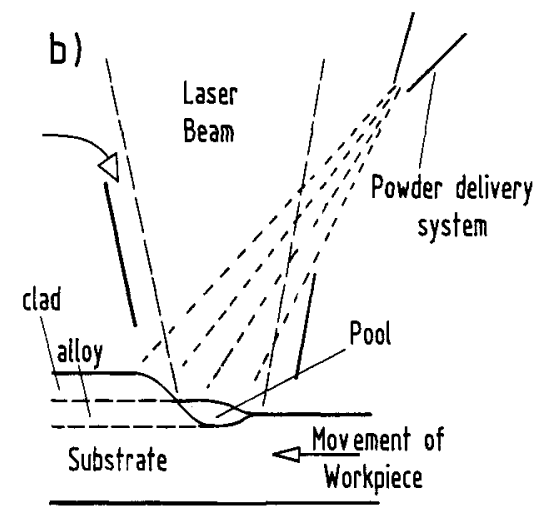

a) predeposition of pre-alloyed material (ref.41), and b) powder injection to the melt (refs.53,67)

In ion beam mixing (refs.51,73) the compositions are controlled accurately by depositing films of different thickness. Mixing of thin film structures by reaction and interdiffusion to enhance adhesion is achieved by the microscopic collision cascades generated by heavy high energetic ion beams of chemically inert $(\mathrm{Xe}+$ ) or reactive ion species such as $\mathrm{N}+, \mathrm{O}+, \mathrm{CO}+$ ions (ref.70).

Metallic and ionically bonded substances with long range and non-directional interatomic forces can retain their structural integrity even after many displacements of host atoms by ion implantation. This is different in covalently bonded substances with their short range, highly directional interatomic bond, where ion implantation will distort the lattice and cause amorphization already at a few atom percent of incorporation (ref.70).

The advantage of LSA and ion implantation techniques over conventional bulk alloying and coating techniques are retainment of the bulk characteristics, conservation of scarce alloy materials (refs.74,75) and high degree of adhesion between substrate and coating. The concern over strategicelement utilization and cost considerations (ref.56) in precious-metal usage has favoured avtivities in surface alloying rather than bulk alloying thus offering materials conservation and cost savings.

\section{EXTENSION OF THERMODYNAMIC AND THERMOPHYSICAL PROPERTY MEASUREMENTS}

\subsection{Problems and requirements}

The rapidly increasing fuel costs and need for improved thermal efficiency of power plants led to an increase in the peak temperatures of the cycles and consequently to the necessity of extending our knowledge on material properties to higher temperatures (ref.76). In reactor technology reliable high temperature thermodynamic and thermophysical data are required for fuel fabrication up to $2000 \mathrm{~K}$, to predict fuel behaviour under anticipated normal operating conditions up to about $2500 \mathrm{~K}$, and for saftey risk assessment up to at least $5000 \mathrm{~K}$.

At temperatures up to $2500 \mathrm{~K}$ chemical reactivity, rate of evaporation, compositional changes, increase in heat transfer, temperature uniformity and loss of material strength are of primary importance. The increase of chemical reactivity needs careful control of the compatibility of sample and container materials, of the solid-liquid and liquid-gas reactions and the kinetics of such high temperature processes. Impurities, porocity, grain size and segregation effects, nucleation and growth may in addition have a profound effect on the property and its measurement. High rates of evaporation of multi-component systems lead to surface depletion of the more volatile component and eventually to changes in the bulk composition. Compositional changes and phase transformations must thus be checked by chemical and structural analysis. The range of crucible materials is limited to refractory metals and ceramics such as tungsten, tantalum, molybdenum and borides, carbides, nitrides, oxides and silicides or to graphite. Most property measurements can, however, still be performed under stationary conditions in or close to thermodynamic equilibrium.

The extension of property measurements up to $5000 \mathrm{~K}$ and above, i.e. far beyond the melting point of refractory materials and in to their critical temperature region (refs.76,77) leads to a number of severe additional constraints imposing short heating times by transient-type dynamic pulse heating techniques (ref.22). The type of constraint depends on the chosen technique for high temperature generation. The appropriate technique is selected on behalf of the property to be determined. The 
investigation of the vaporization behaviour, i.e. the determination of the gaseous species and their partial pressures as a function of surface composition and temperature necessitates evaporation into vacuum. Here heating can be restricted only to the surface region which is even advisable in order to avoid entering into a "burst mode" regime (ref.22). The same applies to all surface properties such as emissivity, surface tension etc. Measurements of volume properties such as density, thermal expansion, heat capacity (ref.25) rely on the achievement of temperature uniformity or the accurate knowledge of the temperature profile throughout the sample. Apart from a rather limited possibility of adaptation of classical heating techniques such as resistance, induction and electron bombardment heating towards higher temperatures, the main techniques developed for these extreme temperatures can be subdivided into chemical flames, exploding wires, shockwaves, imaging and solar heating, electrical discharge, laser and fission/fusion heating.

The four main approaches suited for pulse heating are isobaric resistive heating, laser pulse heating, electron and neutron pulse heating (refs.22,24,26). Each of these transient heating techniques was found to introduce its own experimental and interpretational problems, giving rise to specific requirements in order to guarantee adequate reliability and accuracy in the property measurement. The problems are mainly due to either non uniformity in heating or energy absorption, leading to large radial and axial temperature gradients and expansion forces in the condensate or to not attaining steady state. The problems posed by the measurement of either energy deposition or temperature needs to be solved in all techniques. The various problems have either to be eliminated or their effects accurately enough accounted for by introducing sufficiently high spatial and temporal resolution into the experimental high speed diagnostics.

Laser pulse heating (LPH) including mass spectrometric analysis, Langmuir probe and high tension diode studies (refs.23,24), and a new approach the "Laser-Autoclave-Technique" (LAT) (ref.26) as a combination of pulsed multi-beam laser heating under pressurized inert gas atmosphere, sixwavelength pyrometry, microfocus $x$-ray shadow technique and containment-free acoustic levitation are presented in this paper.

\subsection{Vapour pressure equation of state measurements using laser pulse heating}

The need for experimental equation of state input data for safety risk assessment as required for nuclear fast-breeder oxide fuels has led to the development of laser pulse heating techniques that are not limited to conductive materials. The sample is heated under vacuum by a pulsed high energy laser beam in the nanosecond (ref.78), microsecond (ref.79), and millisecond (ref.80) time scale with multimode or a well-defined Gaussian (refs.22,79) spatial power density profile. The vapour pressure is obtained from the depth profile and mass spectrometric analysis (refs.22-24), the recoil pressure (ref.80) and by Mach disk studies (refs.81,82) and the time-resolved temperature variation.

A schematic display of the laser pulse heating technique is summarized in Fig.7.

The sample is heated in ultra high vacuum up to temperatures from 3000 to $8000 \mathrm{~K}$ using a rectangular Nd:YAG laser pulse of $50 \mu$ s to 200 ps duration with a Gaussian spatial power profile and power densities of the order of $10^{7} \mathrm{~W} / \mathrm{cm}^{2}$. The diameter of the heated target area in the focal spot is 1 to $3 \mathrm{~mm}$. The central target temperature is measured by a multi wavelength pyrometer with a temporal resolution of $10 \mathrm{~ns}$, a spatial resolution of approximately $100 \mu \mathrm{m}$, and a temperature resolution of better than $1 \%$ at $5000 \mathrm{~K}$. (ref.22).

Spectroscopic temperature measurements of the evaporating jet are required as input data to investigate the gas dynamic expansion mechanism at extreme evaporation rates and to estimate backscattering effects due to the transition from the molecular to the hydrodynamic flow.

Charged particle emission was investigated by a combination of mass spectrometric, Langmuir probe and high tension diode studies (ref.23). The aim of the mass spectrometric analysis was to identify the various neutral and ionized gaseous species in the vapour jet, determine their concentration, and compare the results with thermodynamic equilibrium calculations. The aim of the Langmuir probe measurements was to determine the local electron temperature and electron and ion densities at various distances from the surface in order to calibrate the partial ion densities in conjunction with the mass spectrometric ion intensity signals. The aim of the high tension diode studies was to determine the electron and ion work functions, to check the intrinsic ion emission from the heated surface, and to eliminate non-thermal, laser specific multi-photon absorption effects.

The laser pulse heating technique has been applied to both oxide (ref.23) and carbide fuels (refs.22,83) to determine the input data for sensitivity studies of excursion yields as an important factor in hypothetical whole core accident analysis in fast breeder reactors. Laser pulse heating under vacuum gives direct access to mass spectrometric partial pressure analysis and permits a detailed thermodynamic assessment of the system. The properties directly measured or derived are vapour pressure, emissivity, heat capacity, enthalpy and entropy of phase changes. Modifications of this technique allow the measurement of surface tension (ref.84), viscosity and thermal expansion. The major experimental problems due to radial flow phenomena caused by the radial and axial temperature gradients within the heated target area, possible compositional changes at the evaporating surface, ion and electron emission from the surface and the reliability limits have been extensively discussed elsewhere (refs.21-23,83,85). 
Krypton Laser

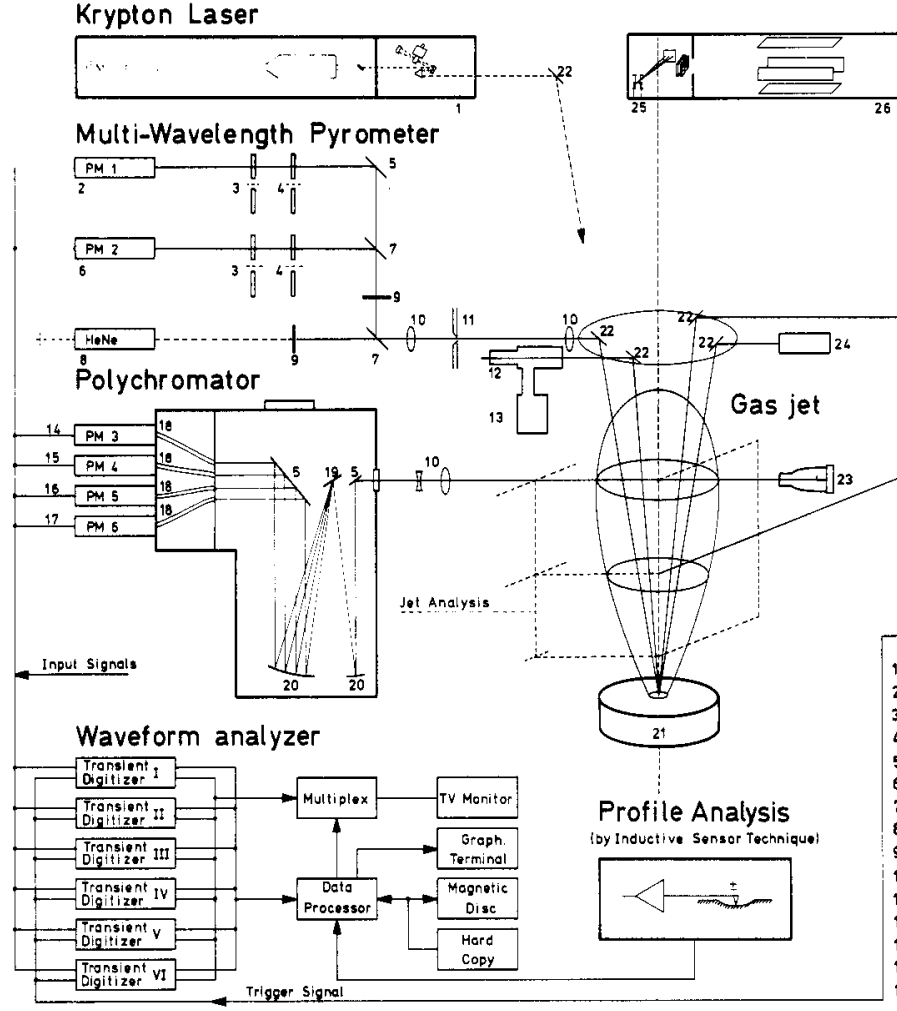

Time-of-Flight Mass Spectrometer

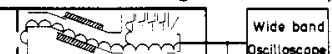

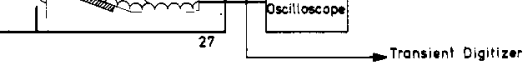

Nd: YAG Laser
428
4

High Speed Camera
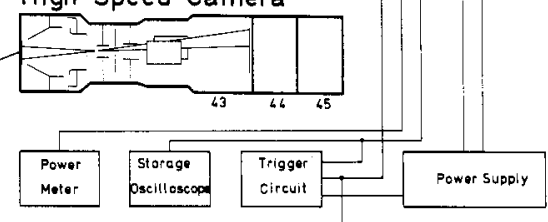

Acousto-Optic Coupler 16 : Photomultiplier $\left(\lambda_{5}\right)$ 31: Mode Selecto Photomultiplier $\left(\lambda_{1}\right)$ 17: Phatomultiplier $\left\{\lambda_{6}\right\}$ 32: Photodiode Interference Filter 18:Fiber Optics 33: Boam Switen Groy Filler 19:Grating 36: Amplifier I Total reflecting Mirror 20: Concave Mirror 35: Foradey Rotator -Photomultolier $\left(A_{2}\right)$ 21:Somple 35: Amplifier II

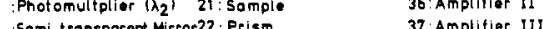

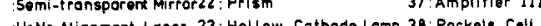

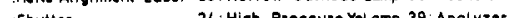
:Shutter 26: High Pressure XoLamp 39: Analyzor 10:0bjectiva 25: ton Source 40: Amplitier IV 11 : Collimator $26:$ Flight Tube $41:$ Thermopile 12 :Microscope 27: Magn Electron Mutipli er 42: Obj ective 13 :TV Camera 2B:Mirpor $23:$ Image Converter 16 : Photomultiplier $\left(\lambda_{3}\right)$ 29: Polarizer 46: Light Intensifier

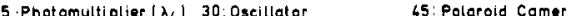

Fig.7: Schematic set-up of laser pulse heating, multi-wavelength pyrometry, mass spectrometry, depth profile analysis, spectroscopy and high speed photography for EOS studies.

\subsection{Heat capacity and density measurements by the laser autoclave technique}

The urgent need for heat capacity and density data of the liquid reactor fuel for safety risk assessment up to at least $5000 \mathrm{~K}$, and the unsatisfactory state of present knowledge concerning these basic thermophysical properties has led to the development of the laser-autoclave-technique (ref.26).

The heat capacity of the fuel affects both the Doppler and disassembly feedbacks (refs. 25,26). It relates the energy to the temperature attained during an excursion and permits the calculation of the amount of energy required before melting occurs. For safety risk assessment the heat capacity of the fuel material should be known within $\pm 10 \%$.

The density is required to calculate the negative reactivity feedback as the volume increases with temperature, in particular upon melting and beyond. Because of the high sensitivity of the heat capacity on volume, liquid density data in this special application are required within $\pm 2 \%$ implying an allowable error of $0.67 \%$ in the determination of the diameter of a sphere (ref.26).

\section{New approach: laser autoclave technique}

The Laser Autoclave Technique (Fig.8) as a combination of pulsed multi-beam laser heating under pressurized inert gas atmosphere, six-wavelength pyrometry, microfocus $x$-ray shadow technique and containment-free acoustic levitation, has been developed to meet these requirements i.e. to extend thermophysical property measurements (heat capacity, density, thermal expansion, emissivity, etc.) far beyond the melting point of ceramic fuel materials (ref.26).

The heat capacity is obtained from the cooling rate. A spherical $\mathrm{UO}_{2}$ sample is heated by four $100 \mathrm{~ms}$ laser beams up to $5000 \mathrm{~K}$ applying beam splitting in tetrahedral configuration (Fig.9).

After switching off the laser pulse heating the temperature is measured as a function of time. In order to eliminate heat losses by vaporization, i.e. restrict to radiation and conduction as the only heat loss mechanisms, laser pulse heating is performed in an autoclave (Fig.10) with sapphire windows under high inert gas pressure. 
The rate at which a hot microsphere cools is then given by the energy balance equation

$$
\frac{4}{3} r^{3} \pi \rho c \frac{d r}{p t}=-4 \pi r^{2}\left(\varepsilon \sigma T^{4}+a T\right)
$$

where $r, \rho, c_{p}, \varepsilon$, are the radius, density, heat capacity and emissivity of the sphere. The energy loss of the sphere is given by the loss through radiaton and convection. At temperatures above $3000 \mathrm{~K}$ the loss rate due to convection is negligible. The energy balance equation reduces to

$$
\frac{d T}{d t}=-\frac{3 \varepsilon \sigma T^{4}}{\rho r c_{p}}
$$

The solution by integration is

$$
\left(\frac{T_{i}}{T}\right)^{3}=1+\frac{9 \varepsilon \sigma T_{i}^{3}}{\rho r_{p}} t
$$

where $T_{i}$ is the initial temperature of the sphere . A plot of $1 / T^{3}$ as a function of $t$ allows to calculate $c_{p}$ directly from the slope of the straight line, provided the total emissivity, radius and density are known.

For typical values of $\mathrm{UO}_{2}$ micropheres $(\mathrm{r}=0.5 \mathrm{~mm}$, $\rho \sim 10 \mathrm{~g} \mathrm{~cm}^{-3}, \mathrm{c}_{\mathrm{p}} \sim 160 \mathrm{~J} \mathrm{~mol}^{-1} \mathrm{~K}^{-1}$ ) the cooling time from an initial temperature of $5000 \mathrm{~K}$ to $4000 \mathrm{~K}$ is of the order of $50 \mathrm{~ms}$.
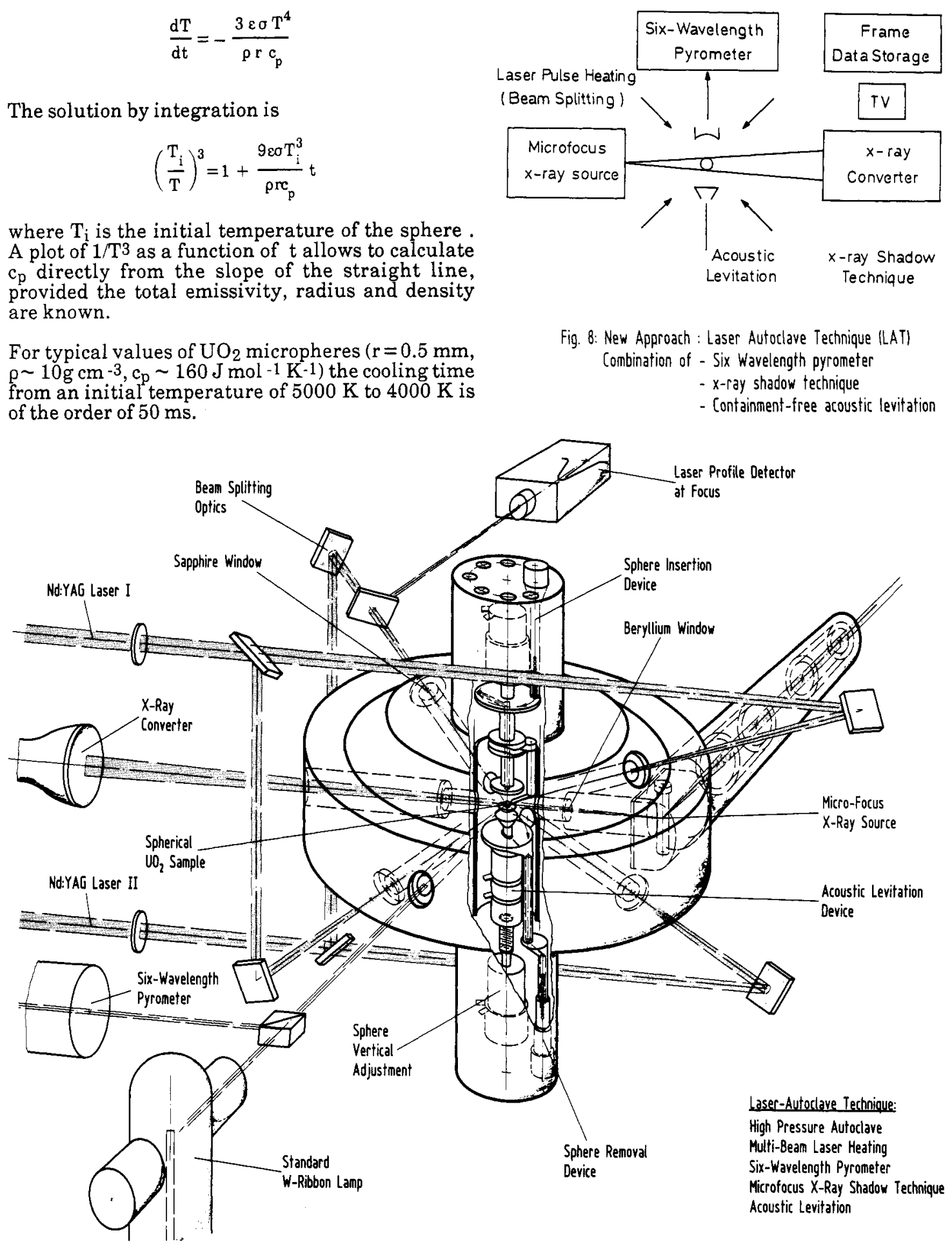

Fig.9: Perspective drawing of tetrahedral laser heating of spherical sample within the high pressure autoclave showing acoustic levitation, pyrometry and $x$-ray shadow technique

Fig. 8: New Approach : Laser Autoclave Technique (LAT) Combination of - Six Wavelength pyrometer

- $x$-ray shadow technique

- Containment-free acoustic levitation 


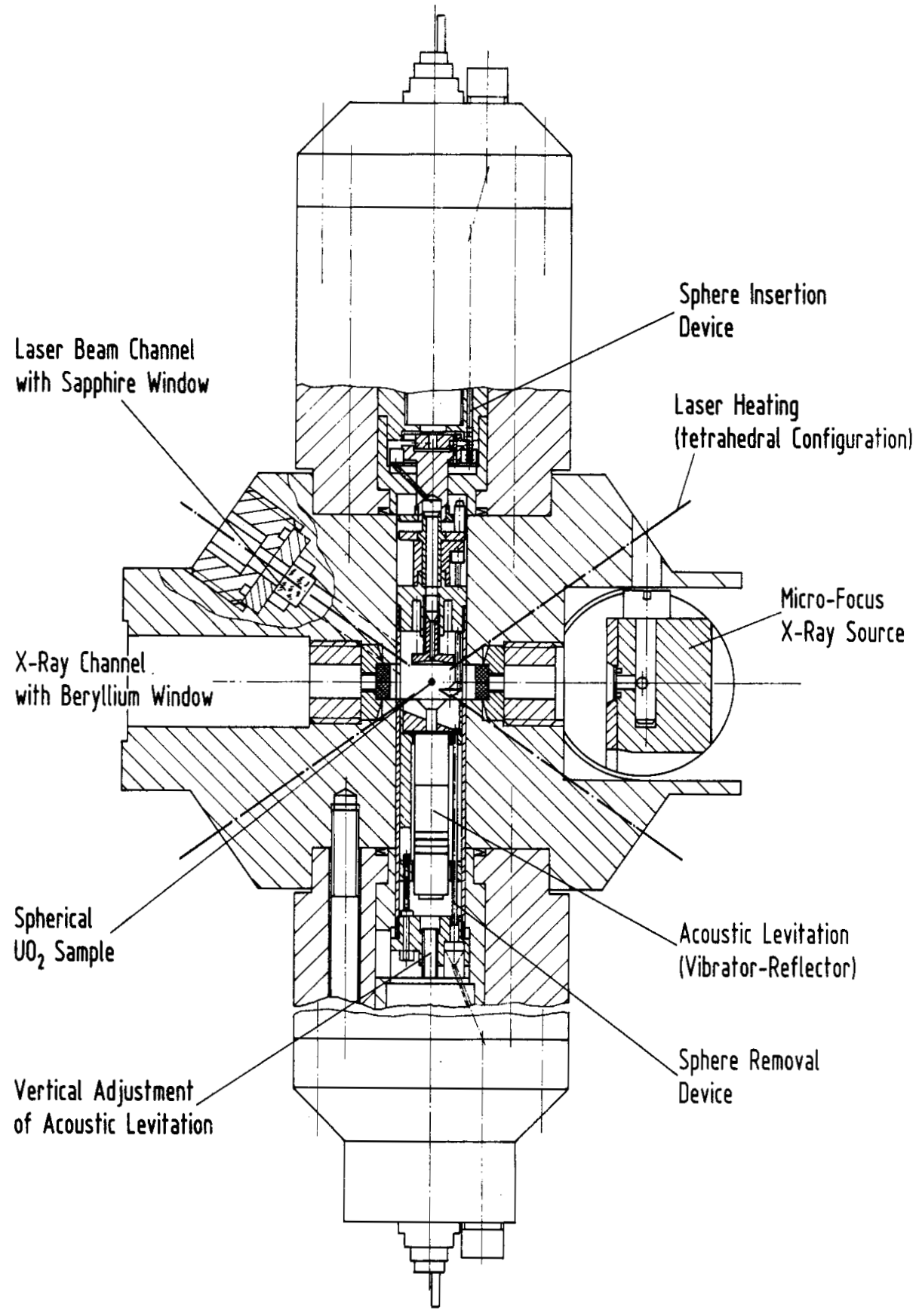

Fig. 10: [ross-section of high pressure laser autoclave

The cooling rate, spectral and total emissivity are measured by a sub-millisecond six-wavelength pyrometer developed in this laboratory (refs.26,86-89). The main requirements of the six-wavelength pyrometer are high temperature, time and spatial resolution, and stability and linearity of the detector response better than $1 \%$. Due to the severe lack of high temperature emissivity data, measurements at six wavelengths are necessary to establish the true temperature and emissivity dependence on wavelength and temperature to evaluate the required total emissivity. The simultaneous measurement at all six wavelengths was necessary because of the fast temperature changes in the transient-type dynamic pulse heating experiments. The image of the heated surface is given on a glass fiber system where the light is split and conducted through six interference filters on to the six Si-photodiode detectors. 
The diameter and density display of the liquid sphere during the heating and cooling cycle are measured by a microfocus $x$-ray shadow technique. It consists of a microfocus $x$-ray source, $x$-ray converter with image intensifier, TV camera, monitor display and frame data storage. The required resolution of $1 \mu \mathrm{m}$ is obtained by an x-ray microfocus of $1 \mu \mathrm{m}$ and magnification up to 40 times the sphere diameter on the $\mathbf{x}$-ray converter.

The spherical liquid $\mathrm{UO}_{2}$ samples are suspended by acoustic levitation (ref.26). A flat levitator (vibrator) and curved reflector, adjusted within the vertical central channel of the autoclave (Fig.10), are piezoelectrically driven by an ultrasonic piston transducer operating at a resonance frequency between 50 to $70 \mathrm{kHz}$ with a $12 \mathrm{~mm}$ diameter radiating front face (refs.26,90). The sphere is levitated by the axial and stabilized by the radial gradients of sound pressure within the tuned standing resonance wave pattern. Due to the short heating pulse duration of $100 \mathrm{~ms}$ wavelength changes with temperature could be neglected.

The advantage of this laser autoclave technique is its almost unlimited application to thermophysical property measurements in high temperature materials research due to containment-free heating up to their critical point temperatures regardless of the conductive or magnetic properties of the material.

\section{REFERENCES}

1. J.T.Luxon and D.E.Parker, Industrial Lasers and Their Applications, Englewood Cliff., N.J. Prentice Hall, Inc. (1985)

2. D.J.Bradley, in Topics in Applied Physics, Vol. 18, ed.S.L. Shapiro, Springer Verlag, Berlin 1977, Ch.2, p.17

3. V.S.Letokhov, Physics Today 33(11), 34 (1980)

4. V.S.Letokhov, Tunable Lasers and Applications, ed. A. Mooradian, T.Jaeger, P.Stokseth, Springer Verlag, New York 1976, p.122

5. A. Baronavski, J.E.Butler, J.W.Hudgens, M.C.Lin, J.R.McDonald and M.E.Umstead, Advances in Laser Chemistry, ed. A.H. Zewail,Springer Verlag, Berlin (1978) p.62

6. T.W.Hänsch, Physics Today 34(1977)

7. G.W.Greenless, D.L.Clark, S.L.Kaufman, D.A.Lewis, J.F.Tonn and J.H.Broadhurst, Optics Communications 23,236 (1977)

8. C.R.Pidgeon and M.J.Colles, Nature 279, 377(1979)

9. E.D.Hinkey, Environmental Science \& Technology 11, 564(1977)

10. P.Yuillot, Spectrochimica Acta, 38B, 1457(1983)

11. R.C.Stern and J.A.Paisner, UCRL-93584 (1985)

12. M.H.Key, Nature $283,715(1980)$

13. J.Nuckolls, L.Wood, A.Thiessen and G.Zimmerman, Nature 239, 139(1972)

14. M.Ross, Rep.Prog.Phys., $48,1(1985)$

15. LLNL Laser Programme Annual Report 1984, ed. M.Louise Rufer and P.W.Murphy, UCRL $50021-84$

D.L. Matthews et al., Demonstration of a soft $x$-ray amplifier Phys. Rev.Lett. 54,2, 110(1985)

16. D.J.Bradley, Endeavour, $\underline{34}, 90(1975)$

17. The Industrial Laser Annual Handbook, ed. D.Belforte and M.Levitt, Penn Well Books, Laser Focus, Tulsa, Oklahoma 1986

18. Laser Material Processing, ed. M.Bass, Materials Processing Theory and Practice, Vol.3, ed. F.Y.Wang, North Holland Publishing Company (1983)

19. D. Turnbull, Metall. Transact.A, 12A, 695(1981)

20. L.Brewer, Methods of Evaluation in IUPAC Handbook of Thermodynamic and Transport Properties of Alkali Metals, ed.R.W.Ohse, Blackwell Scientific Publications, Oxford 1985

21. R.W.Ohse, J.-F.Babelot, C.Cercignani, P.R.Kinsman, K.A.Long, J.Magill, and A.Scotti, 10th Materials Research Symposium on Characterization of High Temperature Vapors and Gases, Gaithersburg 1978, ed. J.W.Hastie, NBS Spec.Pub. 561 , Vol.1,p.83

22. R.W.Ohse, J.-F.Babelot, C.Cercignani, A.Frezzotti, K.A.Long, J.Magill, and A.Scotti, High Temp. Sci., 13, 35(1980)

23. R.W.Ohse, J.-F.Babelot, C.Cercignani, J.-P.Hiernaut, M.Hoch, G.J.Hyland, and J.Magill, J. Nucl. Mat., 130, 165(1985)

24. R.W.Ohse, J. Chem. Soc., Farady Trans., 2, 83(1987)

25. G.J.Hyland and R.W.Ohse, J. Nucl. Mat.,140, 149(1986)

26. R.W.Ohse, C.Cercignani, A.Frezzotti, J.-P.Hiernaut, M.Hoch, G.J.Hyland, J.Magill, T.Matsui, P.Werner, 115 th TMS Annual Meeting, New Orleans March 1986

27. J.F.Ready, Industrial Applications of Laser, New York, Academic Press 1978

28. S.S.Charschan, Laser in Industry, Van Nostrand Reinhold Comp. New York 1972

29. L.J.Hendricks and S.P.Zobrist, Appl. Optics 20, 1880(1981)

30. D.M.Roessler, The Industrial Laser Annual Handbook, 1986 Edition, ed. D.Belforte and M.Levitt, Penn Well Books, Laser Focus, Tulsa, Oklahoma (1986), p.16

31. F.O.Olsen in Lasers in Materials Processing, ed E.A.Metzbower, ASM, Metals Park, Ohio(1983), p.64

32. G.Herziger, The Industrial Laser Annual Handbook, 1986 Edition, ed. D.Belforte and M.Levitt, Penn Well Books, Laser Focus, Tulsa, Oklahoma (1986), p.108 
33. H.F.Brändli, M.Keller, A.Roulier, Laser Focus Magazine 5(1967)

34. L.M.Heglin, The Industrial Laser Annual Handbook, 1986 Edition, ed. D.Belforte and M.Levitt, Penn Well Books, Laser Focus, Tulsa, Oklahoma (1986), p.116

35. D.Schuöcker,The Industrial Laser Annual Handbook, 1986 Edition, ed. D.Belforte and M.Levitt, Penn Well Books, Laser Focus, Tulsa, Oklahoma (1986) p.87

36. R.Rothe, VDI-Fortschrittsberichte, Reihe 2, Nr.113, Düsseldorf (1986)

37. H.Semrau, Laser Magazin, 1.30(1986)

38. K.Reumann, H.Semrau, G.Giebel, K.Mildenstein, VDI Berichte $610.2,173(1986)$

39. T.Van der Wert, The Industrial Laser Annual Handbook, 1986 Edition, ed. D.Belforte and M.Levitt, Penn Well Books, Laser Focus, Tulsa, Oklahoma (1986), p.58

40. K.W.Carlson, Laser Welding, Machining and Materials Processing, ed. C.Albright, IFS Ltd. UK, Spinger Verlag(1986), p.49

41. H.Behnisch, Laser und Optoelektronik $4,385(1985)$

42. J.Eichler, Laser und Optoelektronik 1,34(1987)

43. B.S.Weil, Laser Welding, Machining and Materials Processing, ed. C.Albright, IFS Ltd. UK, Spinger Verlag(1986) p.145

44. M.Ohmine and S.Hiramoto, Laser Welding, Machining and Materials Processing, ed. C.Albright, IFS Ltd. UK, Spinger Verlag(1986) p.65

45. T.K.Kim, M.H.Lee, Y.Kwon, D.J.Ra, H.J.Kim, and Y.Kang, Laser Welding, Machining and Materials Processing, ed. C.Albright, IFS Ltd. UK, Spinger Verlag(1986) p.59

46. C.Banas, The Industrial Laser Annual Handbook, 1986 Edition, ed. D.Belforte and M.Levitt, Penn Well Books, Laser Focus, Tulsa, Oklahoma (1986) p.69

47. R.F.Duhamel and C.M.Banas, Laser in Materials Processing, ed. E.A.Metzbower, ASM, Metals Park, Ohio (1983) p.209

48. G.Dearnaley, in Surface Engineering, Surface Modification of Materials, ed. R.Kossowsky, S.C.Singhal, Martinus Nijhoff Publishers, Dordrecht, Boston Lancaster 125(1984)

49. B.R.Appleton, B.Sartwell, P.S.Peercy, R.Schaefer, R.Osgood, Mat.Sci.Eng., 70, 23(1985)

50. C.W.Draper, J.Metals, 24(1982)

51. B.H.Kear, J.W.Mayer, J.M.Poate, P.R.Strutt, Metallurgical Treatises, ed. J.K.Tien and J.F.Elliott, 321(1981) TMS-AIME

52. F.D.Seaman, The Industrial Laser Annual Handbook, 1986 Edition, ed. D.Belforte and M.Levitt, Penn Well Books, Laser Focus, Tulsa, Oklahoma (1986) p.147

53. G.Sepold, SURTEC-Kongress 1981, p.323, VDI(1981)

54. I.W.Boyd, J.I.B.Wilson, Nature $287,278(1980)$

55. C.W.White, W.H.Christie, B.R.Appleton, S.R.Wilson, and P.P.Pronko, Appl.Phys.Lett. 33(7), 662(1978)

56. C.W.Draper and J.M.Poate, Int. Met. Rev., 30, 85(1985)

57. C.W.Draper, C.A.Ewing, J.Metals Science $1 \overline{9}, 3815(1984)$

58. P.S.Peercy, D.M.Follstaedt, S.T.Picraux and W.R.Wampler, in Laser and Electron Beam Interactions with Solids, ed. B.R.Appleton and G.K.Celler, 401(1982) New York, North-Holland

59. A.Wolthuis and B.Stritzker, Journal de Physique 44, C5-489(1983)

60. L.A.Davis and R.Hasegawa, Metallurgical Treatises, ed. J.K.Tien and J.F.Elliott, 301(1981) TMS-AIME

61. C.-J.Lin and F.Spaepen, Acta Metall. 34, 1367(1986)

62. C.-J.Lin and F.Spaepen, Appl. Phys. Lett. 41, 721(1982)

63. C.-J.Lin and F.Spaepen, Proc.Mater.Res.Soc. 28, 75(1984)

64. C.-J.Lin, F.Spaepen and D.Turnbull, J.Non.Crystallogr.Soc. 61-62, 767(1984)

65. R.C.Ruhl, B.C.Giessen M.Cohen and N.J.Grant, Acta Metall. 15, 1693(1967)

66. P.Duwez, R.H.Willens and W.Klement, J.Appl.Phys., $32,1136(1960)$

67. W.M.Steen, The Industrial Laser Annual Handbook, 1986 Edition, ed. D.Belforte and M.Levitt, Penn Well Books, Laser Focus, Tulsa, Oklahoma (1986) p.158

68. E.F.Semiletova and T.H.Dumbadze, Laser in Manufacturing, LIM-2, ed. M.F.Kimmit, IFS Ltd. and North Holland (1985), p.97

69. S.S.Lau, Laser and Electron-Beam Solid Interactions and Materials Processing, ed. J.F.Gibbons, L.D.Hess and T.W.Sigmon, Elsevier North Holland (1981) p.547

70. G.Dearnaley, Surface Eng., 2, 213(1986)

71. R.Valori, D.Popgoshev and G.K.Hubler, J.Lubr.Technol., 105,534(1983)

72. J.M.Williams, R.A.Buchanan, Mater.Sci.Eng. 69, 237(1985)

73. W.A.Grant and J.S.Colligon, Vacuum 32, 675(1982)

74. P.G.Moore and E.McCafferty, Int.Congress met.corr.Toronto 1984 Vol.2, 636(1984)

75. W.L Swager, Battelle Today, 18, 3(1980)

76. R.W.Ohse, J.-F.Babelot, J.Magill, M.Tetenbaum, in IUPAC Handbook of Thermodynamic and Transport Properties of Alkali Metals, ed. R.W.Ohse, Blackwell Scientific Publications, Oxford 1985 ch.6.1, p.329

77. R.W.Ohse and H.v.Tippelskirch, High Temp.-High Press., 9,367(1977)

78. N.Asami, M.Nishikawa and M.Taguchi in Thermodynamics of Nuclear Materials, Vienna 1974, Proc. IAEA, Vienna (1975) Vol.1, p.287.

79. R.W.Ohse, P.G.Berrie, H.G.Bogensberger and E.A.Fischer in Thermodynamics of Nuclear Materials, Vienna 1974, Proc. IAEA, Vienna (1975) Vol.1, p.307.

80. M.Bober, H.U.Karow amd K.Schretzmann, in Thermodynamics of Nuclear Materials, Vienna 1974, Proc. LAEA, Vienna (1975) Vol.1, p.295

81. H.C.Tsai, A.Covington, and D.R.Olander, Annual Report LBL 6016 (1976)

82. R.W.Ohse, J.-F.Babelot, A.Frezzotti, K.A.Long, J.Magill, High Tem.-High Press., 12, 537(1980) 
83. R.W.Ohse, J.-F.Babelot, K.A.Long, J.Magill inThermodynamics of Nuclear Materials, Jülich 1979, Proc. IAEA, Vienna 1980, Vol.1, p.171

84. J.Magill and R.W.Ohse, J.Nucl.Mat., 71, 191(1977)

85. R.W.Ohse, J.-F.Babelot, P.R.Kinsman, K.A.Long, and J.Magill,High Tem.-High Press., 11, 225(1979)

86. J.-F.Babelot J.Magill and R.W.Ohse, in Temperature its Measurement and Control in Science and Industry, ed.J.F.Schooley, Amer.Inst.Physics, New York (1982) Vol.V, p.439

87. A. Cezairliyan, J.-F.Babelot, J.Magill and R.W.Ohse in Theory and Practice of Radiation Thermometry, ed. D.P.DeWitt and G.D.Nutter, Ch.8, in press

88. J.-P.Hiernaut, R.Beukers, W.Heinz, R.Selfslag, M.Hoch and R.W.Ohse, High Tem.-High Press., in press

89. J.-P.Hiernaut, R.Beukers, M.Hoch, T.Matsui,R.W.Ohse, High Tem.-High Press., in press

90. J.Magill, F.Capone, R.Beukers, P-Werner, and R.W.Ohse, High Tem.-High Press., in press 